\title{
An overview of the tumor microenvironment, from cells to complex networks (Review)
}

\author{
OVIDIU FARC and VICTOR CRISTEA
}

Immunology Department, 'Iuliu Hatieganu' University of Medicine and Pharmacy, 400012 Cluj-Napoca, Romania

Received August 28, 2020; Accepted September 29, 2020

DOI: $10.3892 /$ etm.2020.9528

\begin{abstract}
For a long period, cancer has been believed to be a gene disease, in which oncogenic and suppressor mutations accumulate gradually, finally leading to the malignant transformation of cells. This vision has changed in the last few years, the involvement of the tumor microenvironment, the non-malignant part of the tumors, as an important contributor to the malignant growth being now largely recognized. There is a consensus according to which the understanding of the tumor microenvironment is important as a means to develop new approaches in the therapy of cancer. In this context, the present study is a review of the different types of non-malignant cells that can be found in tumors, with their pro or antitumoral actions, presence in tumors and therapeutic targeting. These cells establish complex relations between them, through cytokines, exosomes, cell adhesion, co-stimulation and co-inhibition; these relations will also be examined in the present work.
\end{abstract}

Correspondence to: Dr Ovidiu Farc, Immunology Department, 'Iuliu Hatieganu' University of Medicine and Pharmacy, Strada Victor Babeș 8, 400012 Cluj-Napoca, Romania

E-mail: farc.ovidiu@yahoo.com

Abbreviations: IL, interleukin; CCL, CXCL, chemokines; EGF, epidermal growth factor; FGF, fibroblast growth factor; VEGF, vascular endothelial growth factor; MMP, matrix metalloproteinase; TAM, tumor associated macrophage; TGF $\beta$, transforming growth factor- $\beta$; TLR, Toll-like receptors; PDGF, platelet-derived growth factor; CAF, cancer-associated fibroblast; SDF, stromal cell-derived factor; ROS, reactive oxygen species; ECM, extracellular matrix; TME, tumor microenvironment; GF, growth factors; MDSC, myeloid-derived supressor cell; TNF $\alpha$, tumor necrosis factor- $\alpha$; PGI2, prostaglandin I2; NO, nitric oxide; LPS, lipopolysaccharide; Ang, angiopoietin; Hif-1, hypoxia-inducible factor-1; NET, neutrophil extracellular trap; CTL, cytotoxic T lymphocyte; DAMPs, damage-associated molecular patterns; LT, LB, T, B lymphocytes; NK LTs, natural-killer lymphocytes; APC, antigen-presenting cell; DC, dendritic cell; ADCC, antibody-dependent cellular cytotoxicity; Th, T-helper lymphocyte; T, Breg, T, B-regulatory lymphocyte; PDL-1, Programmed death-ligand 1; CTLA-4, cytotoxic T-lymphocyte-associated protein 4; TIM-3, T cell immunoglobulin and mucin-domain containing 3 IDO-Indoleamine 2, 3-dioxygenase; CAR, chimeric antigen receptor; MHC, major histocompatibility complex

Key words: microenvironment, biogenesis, immunity, network

\section{Contents}

1. Introduction

2. Cellular participants to the tumor microenvironment

3. The tumor microenvironment, from biogenesis to complex relations

4. Conclusions and perspectives

\section{Introduction}

According to the general logic of tissue architecture and dynamics, a tissue that expands needs to build a vascular network, an interstitium and it needs the help of other supporting cells in order to survive and to grow. This is the case of the epithelia that regenerate, of the embryo that develops, of wounds that heal and, finally, of benign and malignant tumors (1).

In the meantime, even if it has its independent growth, the tumoral tissue is connected with the rest of the body; different cells infiltrate it, either as homeostatic elements, or as an attempt to fight against it, or even recruited by the tumor to help it, contributing in these different ways to the shaping of the tumoral growth (2).

These interactions proved to be important in the development of tumors and are the object of the present review.

\section{Cellular participants to the tumor microenvironment}

Cells of the innate immune system and other stromal cells Macrophages. They have important functions as the first line of defense against pathogens and tissue damage: phagocytic, antigen-presenting, inflammatory cytokines and chemokine secretion (3).

According to these roles, macrophages can be found in different activation states, M1 state for inflammation and immune defense, and M2 for tissue homeostasis and regeneration. In fact, the spectrum of macrophage activation is much more complex and intermediate forms between these states can be found (4). The macrophage is a versatile cell and transitions between states can occur, under the influence of external conditions and cytokine milieu.

In cancer, macrophages are thought to be recruited by local conditions-hypoxia and necrosis- and by cytokines and chemokines from the tumor cells, such as colony stimulating factor-1 (CSF-1), interleukin 34 (IL34), as well as IL6, 
C-C motif chemokine ligand 2 (CCL2) or CXCL10. They are mainly in the M2 state, produce IL10, transforming growth factor $\beta$ (TGF $\beta$ ), growth and angiogenic factors like epidermal growth factor (EGF), fibroblast growth factor (FGF), vascular endothelial growth factor (VEGF), matrix metalloproteinases (MMPs), chemokines (CCL2, 5, 3, 8, 22), they do not secrete IL12 and do not present tumor antigens. They are called tumor associated macrophages (TAMs) and they contribute to the immune suppression and angiogenesis, migration and invasion and recruit other immune cells (reviewed in 5).

There is also a M1-Th1 component in tumors, triggered by tumor antigens, mainly in the initial stages, which contributes to the antitumor defense (6).

What seems to determine a protumoral profile in macrophages is the exposure to factors from the tumor (ILs 4, 6 , 10, TGF $\beta$, exosomes), while Toll-like receptors (TLR) ligation through damage-associated molecular patterns (DAMPs) or agonists or exposure to interferon- $\gamma$ (IFN $\gamma$ ) will turn them into antitumoral macrophages (5).

The presence of tumoral macrophages is generally linked to an unfavorable prognosis (7). By consequence, tumoral macrophages are considered for inhibition (Table I). Given the versatility of these cells, 'educating' them is also taken into account (8).

Fibroblasts. They are the main component of the connective tissue and also of the tumor stroma; they secrete the intercellular matrix and fibrils, sustain tissues, contribute to the tissue and wound healing, to fibrosis and, when activated, to inflammation. Specific markers are vimentin, smooth muscle actin- $\alpha$ (SMA $\alpha$ ), fibroblast activation protein (FAP) (9).

According to these roles, there are sub-populations of fibroblasts: tissue resident fibroblasts, which realize tissue turnover and sustaining, fibroblasts with regeneration function that migrate to injured tissues and contribute to healing, inflammatory fibroblasts, activated by immune cells; there are also sub-populations of fibroblasts specific for each body region, with specific HOX gene codes (10).

In cancer, fibroblasts are induced by tumor cells, together with blood vessels, through factors such as FGF or PDGF (platelet-derived growth factor), as well as by hypoxia in tumors. They have a predominantly activated state, due to the action of IL1, TGF $\beta$, PDGF, stromal cell-derived factor (SDF) and reactive oxygen species (ROS) (11) and are known as cancer-associated fibroblasts (CAFs). They are the majority of the tumor stromal cells.

CAFs secrete the extracellular matrix (ECM) and also active substances such as cytokines, growth factors (GFs) like TGF $\beta$, HGF, SDF and MMPs, through which they shape the microenvironment of tumors, they are angiogenic through VEGF and PDGF and support the tumor growth and invasion. They usually negatively modulate the antitumor immunity through chemokines (CCL2 and 5) and cytokines (TGF $\beta$ ), attracting T-regulatory lymphocytes (T regs), myeloid-derived suppressor cells (MDSCs) and also helping tumor cells to migrate (through CXCL12) $(11,12)$.

Fibroblasts are also subjects of immunotherapy (Table I) (reviewed in 12).

Endothelial cells. Together with pericytes, they form the boundaries of capillaries and regulate the flow of substances and cells from within the vessel out and backwards. They are dynamic structures, responding to cytokines, growth factors and other active substances like IL1, tumor necrosis factor- $\alpha$ (TNF $\alpha$ ), IFN $\gamma$, IL4, PGI2-prostaglandin I2, NO-nitric oxide, VEGF, FGF and secreting active substances (IL1, TNF $\alpha$, IL6, IL8, IL20, IL33, LPS-lipopolysaccharide), through which they participate in the inflammatory processes and augments them when needed (13).

The endothelial cell also participates in the regeneration and healing processes, responding to angiogenic factors (VEGF, FGF, Ang-angiopoietin) and secreting them (13).

In tumors, due to the multiplication of cancer cells, there is hypoxia, which leads to the hypoxia-inducible factor-1 (Hif-1)-dependent augmentation of VEGF and other angiogenic factors (14); this causes angiogenesis. The vessels that form are different from normal vessels, being tortuous, disorganized, with few or no pericytes and to some of their length without walls (15).

The result is a modified metabolism in tumors, changes in the physical qualities of the ECM, metastasization, abnormal distribution of drugs and abnormal trafficking of immune cells to and from the tumor.

Neutrophils in tumors. Their normal function is to respond to pathogens at the beginning of the immune response, through phagocytosis and extracellular traps (NETs). Through the cytokines they produce, they amplify the response of other cells in inflammation. In addition, they present antigens and contribute to the end of the inflammatory process, by phagocytizing dead cells (16).

There are fewer neutrophils than macrophages in tumors, attracted by chemokines such as IL8 from the tumor cells or by inflammation and necrosis. They are short-lived, but they have a turnover and contribute to the process in two opposite ways: they can be antitumoral (N1 neutrophils), especially in a milieu with IL12 and TNF, and this effect requires the presence of $\mathrm{CD}^{+}$cells (17).

They can be protumoral through the secretion of MMP9, HGF and VEGF, where the neutrophil depletion leads to the cancelling of the angiogenic switch (18). This is the natural state of neutrophils in tumors and this is one of the reasons for which blocking IL8 reduces tumor growth (17). TGF $\beta$ is believed to be the main cause for this protumoral profile, called N2, while IFN $\gamma$ turns the neutrophils into N1 tumoricidal cells (17).

As a rule, neutrophilic infiltration in solid tumors is associated with worse prognosis (19). A greater number of circulating neutrophils, reflected in the neutrophil/lymphocyte ratio, is associated with worse prognosis in many tumors (20).

Eosinophils in tumors. The eosinophils have a role in clearing parasitic and some bacterial infection. They participate in the immune response, especially in the Th2 type. They are activated by IL5 (3) and secrete more than 30 cytokines, such as IL1, 2, 3, 4, 5, 9, 10, 12, 13, 17, 25, IFN, TNF, chemokines such as CCL11, MIP, MCP, CCL5 and growth factors NGF, PDGF, EGF, TGF $\alpha$ and $\beta$ (21).

Eosinophils were shown to be tumoricidal in some tumors, where the presence of $\mathrm{CD} 8^{+}$cells was needed (22). However, they are an important source of IL4, which is Th2 polarizing and protumoral (23). Nonetheless, eosinophils are effective 


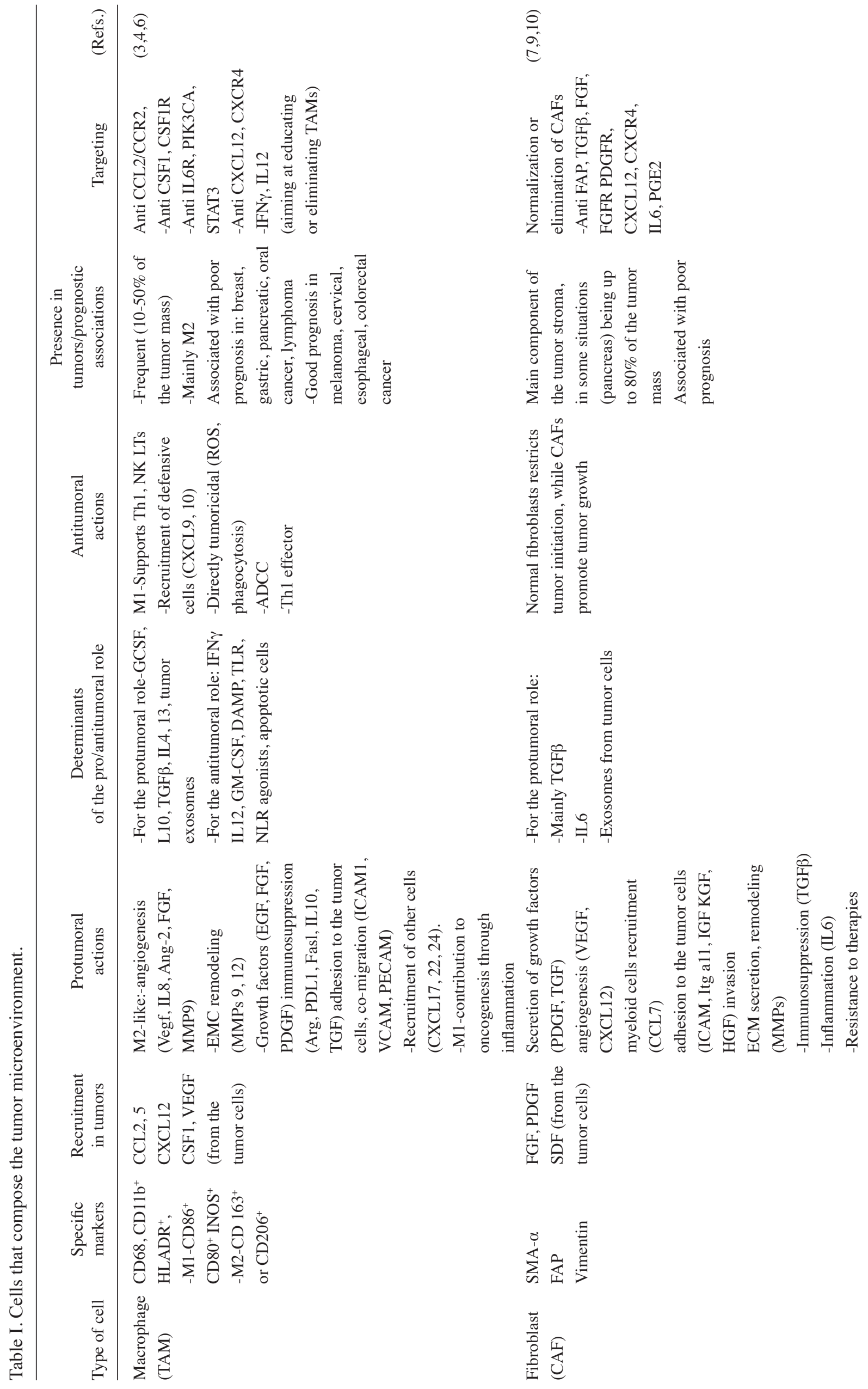




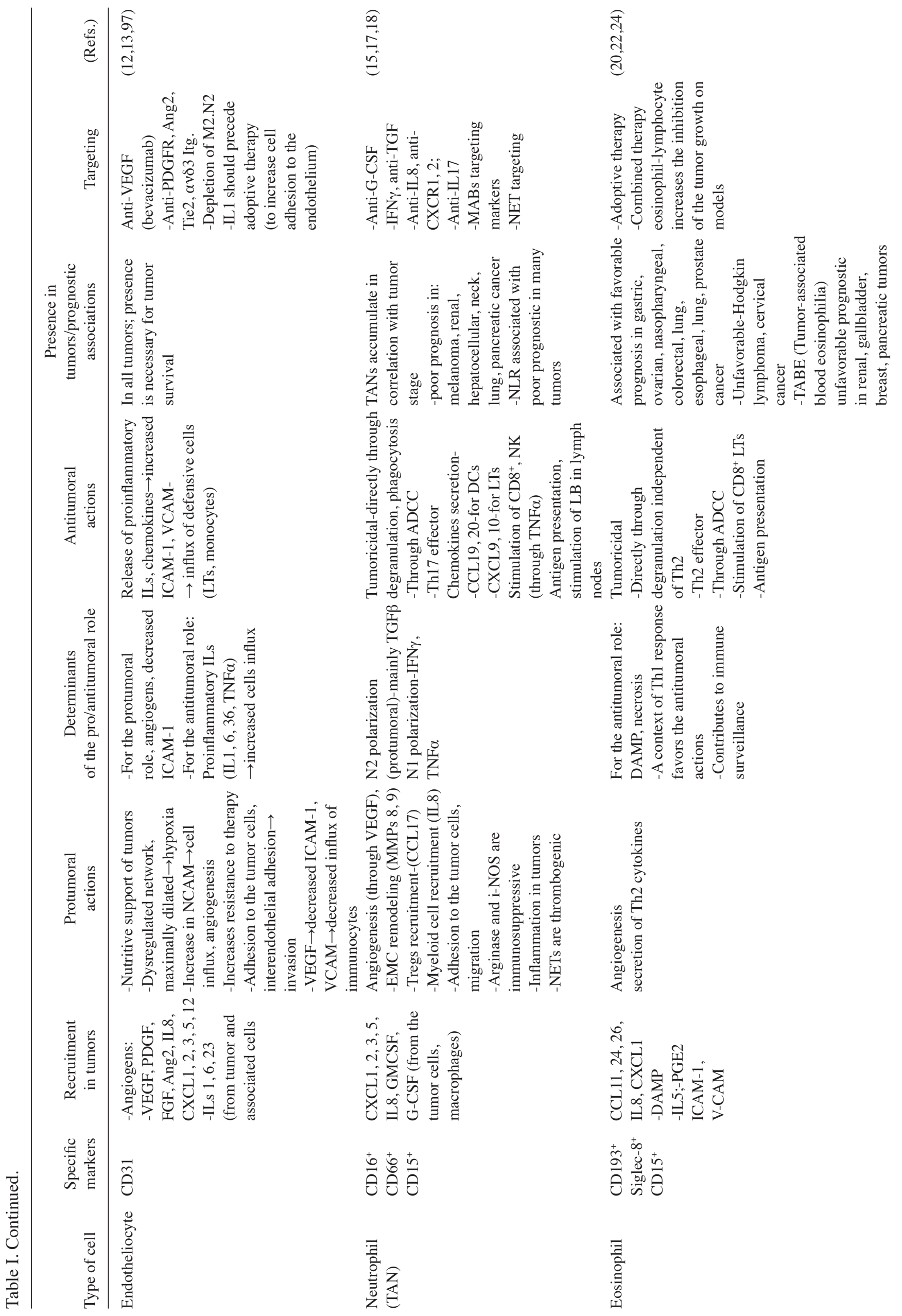




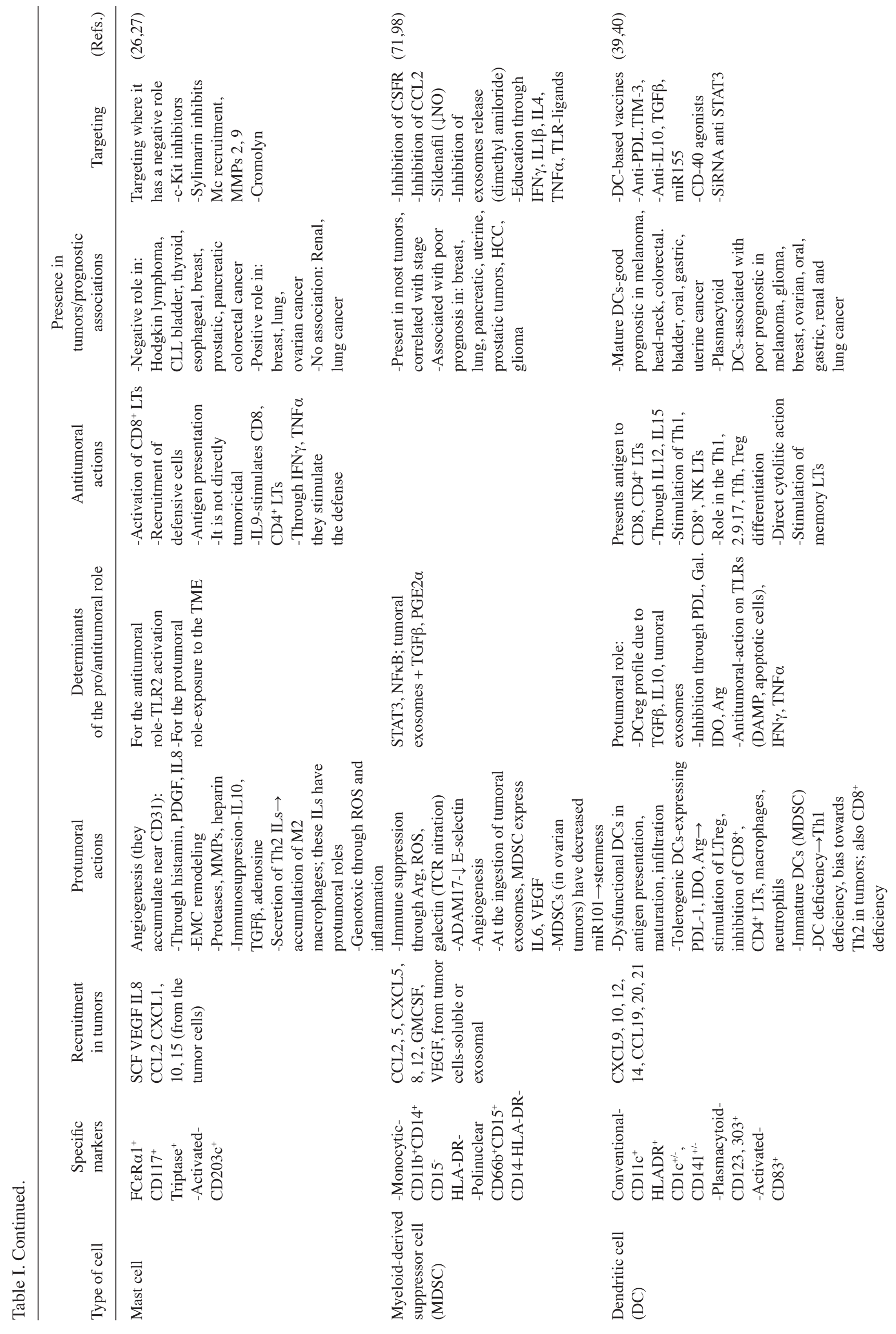




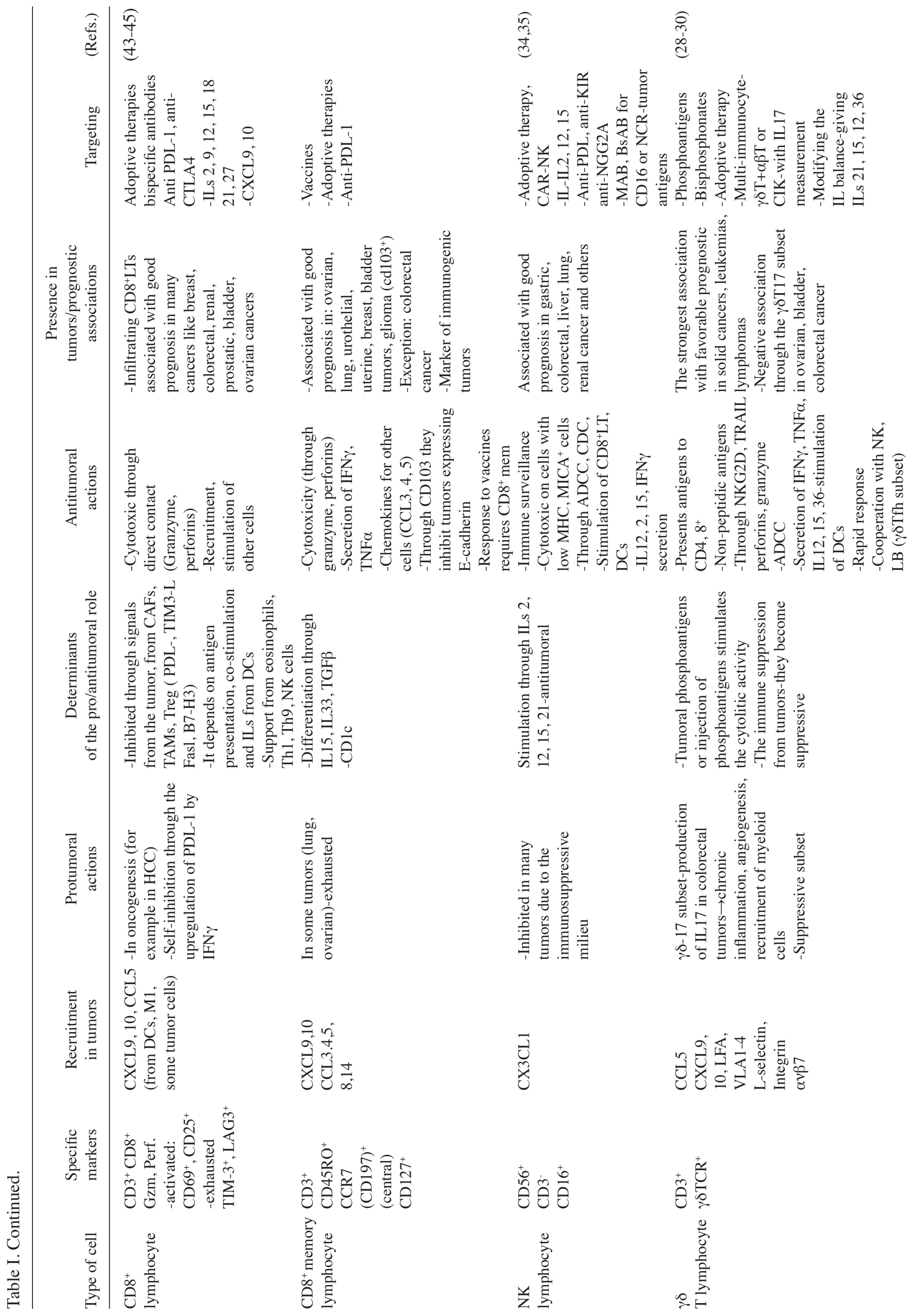




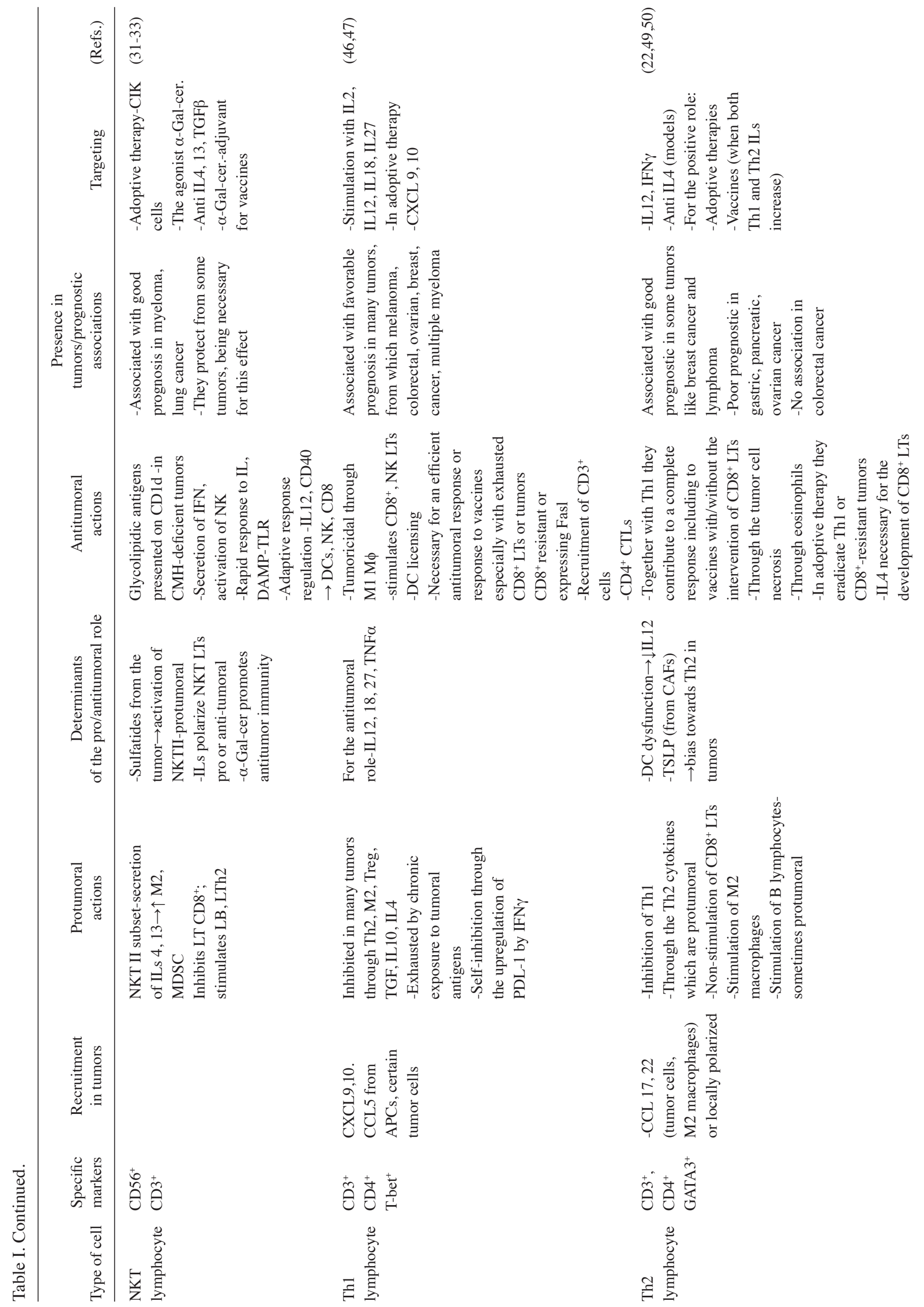




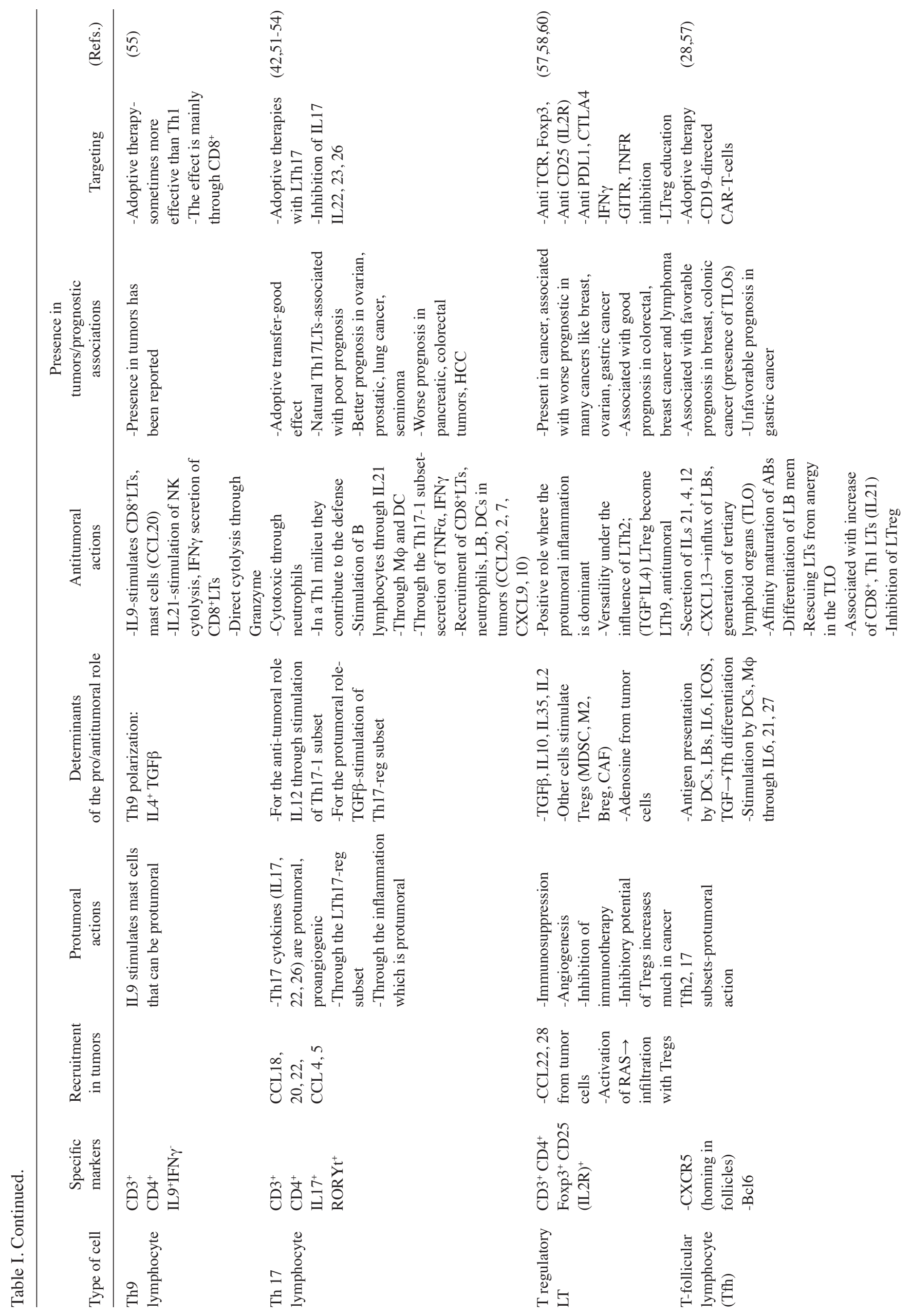




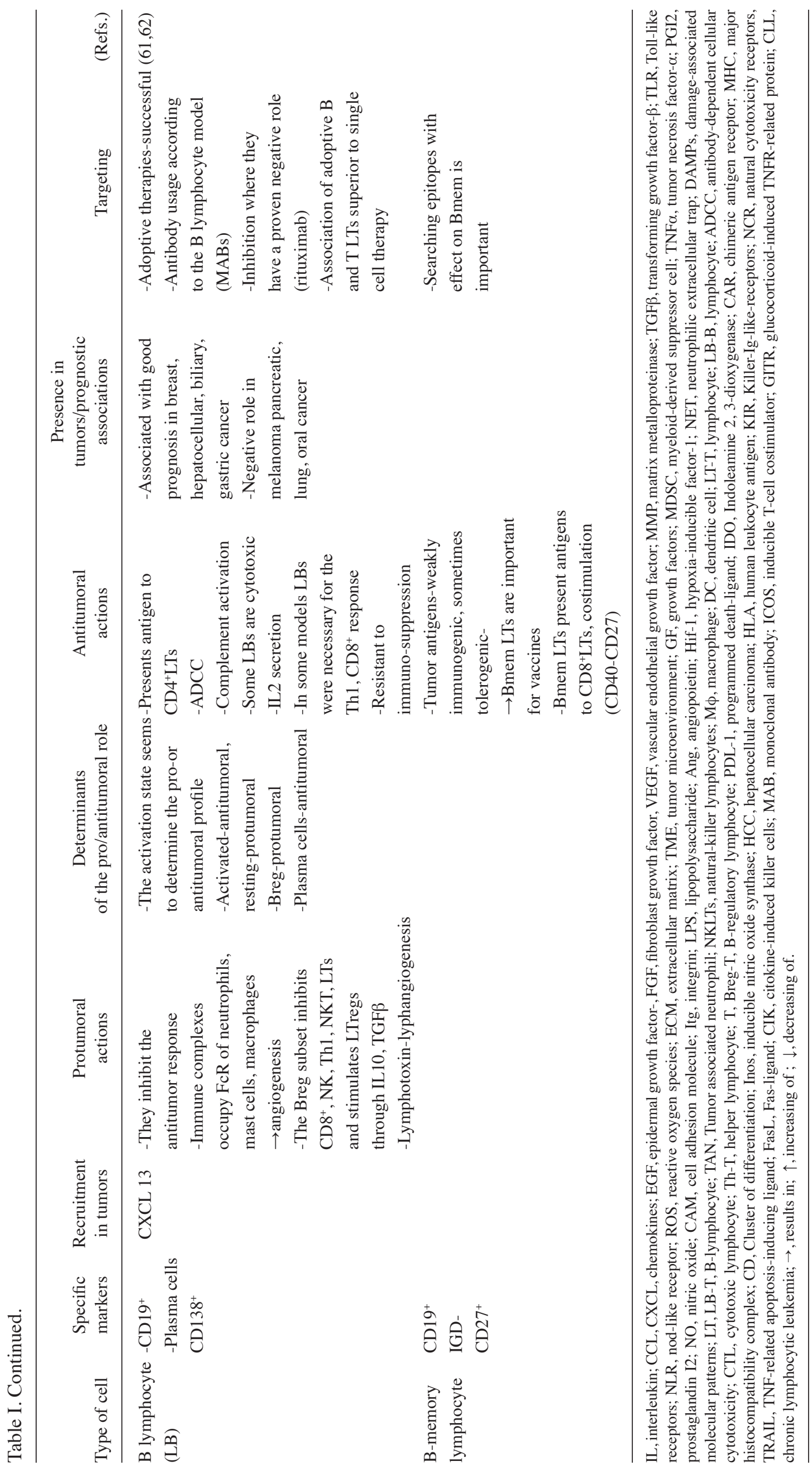


in the CTL (cytotoxic T lymphocyte)-resistant tumors on models (24) and in tumors with cells engineered to express IL4 there was a rich infiltration with eosinophils and macrophages, which had tumoricidal effect (25).

The eosinophilic infiltration in tumors (except Hodgkin lymphoma) is associated with good prognosis (26).

Mast cells in tumors. Mast cells are cells with an important role in the innate and adaptive immunity. They are involved in the immune defense of the mucosal barriers and express TLRs 1-7, 9 and Fce receptors (FceR). They recognize DAMPs and release inflammatory mediators contained in their granules or cytokines (IL1, 6, TNF) and recruit other cells such as neutrophils, eosinophils, $\mathrm{CD}^{+}$and natural-killer lymphocytes (NK LTs). The mast cells present antigens via MHCI or II (major histocompatibility complex), they stimulate DCs (dendritic cells) and contribute to angiogenesis (27).

In tumors, mast cells can play either pro or antitumoral role (Table I) (reviewed in 28). Mast cells exposed to the tumor microenvironment are mostly protumoral, while the action on their TLR-2 receptors has been shown to stimulate an antitumoral profile in them (29).

\section{Lymphocytes of the innate immune system}

$\gamma \delta T$-cells. They form $0.5-5 \%$ of the lymphocyte population, being present mostly in the gut and in the skin. $\gamma \delta$ T-cells act on phosphoantigens, but they also present antigens to $\mathrm{CD}^{+}$ and $\mathrm{CD}^{+}{ }^{+}$LTs and cooperate with NKs (3). Of all immune cells in tumors, it is the subset with the strongest association with good prognosis in cancer (30).

However, there are also protumoral subsets: $\gamma \delta-17$ LTs, which secrete IL17, and a suppressive subset (31). The suppressive TME can turn $\gamma \delta$ LTs into suppressive LTs. They are extensively studied for adoptive and other therapies (Table I) (reviewed in 32).

NKT cells. They respond to hydrophobic antigens, presented by CD1d-type MHC. There are two main subsets of NKT, type I with an invariant T-cell receptor (TCR), which is antitumoral by stimulating DCs, $\mathrm{CD}^{+}$and NK LTs, and type II, which is mostly protumoral (33).

There are also NKT-17, Tfh ( T follicular)-like and Treg-like subsets, with dominant protumoral activity (34).

NKT cells are also intensively studied for adoptive therapies (CIK cells), for selective stimulation of NKT1 with $\alpha$-galactosyl-ceramide ( $\alpha$-Gal-Cer), for interleukin therapy and others (reviewed in 35) (Table I).

NK lymphocytes. They are main antitumor defenders acting on cells with low level of self-proteins (MHC-I) like some tumor cells. They also possess NKG2D receptors for atypical MHC, such as MICA and Fc $\gamma$ receptors, through which they perform antibody-mediated cell destruction (ADCC). They stimulate $\mathrm{CD}^{+}$LTs and DCs through the IFN $\gamma$ they secrete, receiving in turn support from Th1 (T-helper 1 lymphocyte), Th9, CD8 ${ }^{+}$ LTs and M1 macrophages through ILs 9, 12, 15, 21 and type I and II IFNs $(3,36)$. NK cells often become exhausted and suppressed in the inhibitory TME.

They are also investigated for adoptive cell therapy, CAR-NK therapy and others (reviewed in 37) (Table I).
Innate lymphoid cells (ILCs). ILCs possess CD127 (IL7R) and have three main subsets: ILC1 that secrete IFN $\gamma$, having some antitumoral activity (38), ILC2, with pattern of secretion such as Th2 LTs and ILC3, with secretion pattern like Th17 LTs. Intervention of these subsets in cancer resembles that of their adaptive counterparts (36). An antitumoral role has been found for ILC3 in some models (39).

Dendritic cells (DCs). DCs are a heterogeneous cell population present in every tissue and they are professional antigen-presenting cells to LTs. They also secrete cytokines (ILs 1, 2, 6, 12, 15, 18, 37, 23, 27, 7, 37, 31, 10, IFNs) and chemokines (IL8, IL16, CCL9). They express MHC II type proteins. DCs have myeloid or plasmacytoid origin. Depending on the type of antigen exposure and cytokines they secrete or are exposed to, DCs contribute to the Th1, Th2, Th17 polarization or to immune tolerance (40).

In cancer, dendritic cells present tumor antigens to LTs, their number being linked to good prognosis (41). Their depletion leads to the depletion of LTh1 cells, which is detrimental. Tumor cells influence infiltrating DCs, lowering their number and antigen presenting capabilities. They become tolerogenic DCs, which contribute to the immune suppression in the TME and accumulation of Treg cells. Cytokines from the tumor (IL10, TGF $\beta$, VEGF, low IL12) and activation of PD receptors contribute to this (reviewed in 42). Certain miRNAs (micro-RNAs) also influence the behavior of DCs (43).

\section{Cells of the adaptive immune system}

$C D 8^{+} T$ lymphocytes (CTLS). CTLs represent the main antitumor defenders in the human organism; they act after tumor antigen presentation by DCs (1), also receiving support from Th1, Th9 and M1 macrophages (reviewed in 44). CD8 ${ }^{+}$LTs are active especially in the earlier stages of the tumor development. Later, they develop exhaustion and apoptosis due to the activation of programmed death (PD) receptors and to the immunosuppression of the TME (45).

The presence of $\mathrm{CD}^{+}$lymphocytes is associated with good prognosis in many cancers (46). Given its position as key player in the antitumor immune defense, this subset is the most extensively used in different immunotherapeutic approaches, immune checkpoint blockade, adoptive therapies, bispecific antibodies, interleukin therapy, chimeric antigen receptors (CAR)-engineered cells and others (reviewed in 47) (Table I).

$C D 4^{+} T$ lymphocytes. They are in different states of polarization, depending on which cytokine combinations act on them (1):

The Th1 (T-helper-1) subset polarizes in the presence of IL12 from M1 macrophages and IFN, to which also IL18, IL27, IL1 $\alpha$ contribute; they are also contributors to the antitumor defense (48) (Table I). It has been shown that an intact $\mathrm{CD}^{+}{ }^{+}$component is necessary for an efficient antitumoral response (49).

The Th2 subset is polarized by ILs 4, 13, 19, 25 and 33 from mast cells, $\mathrm{NK}$ and $\mathrm{CD}^{+}$mem (CD $4^{+}$-memory) cells $(1,22)$ and secrete Th2 cytokines such as ILs $4,5,10$, $13,25,31,33$. In tumors, they are not favorable to the defense process, because of the secretion of IL 4 and 13 that inhibit the 
Th1 response, and of the cytokines mentioned above, which have mainly a pro-tumoral effect (50). Until recently, the Th2 subset was considered almost entirely protumoral, but in the light of recent data, it was shown that Th2 lymphocytes can also contribute to the antitumor defense, being necessary for some of its observed effects $(25,51)$ (Table I). This is the reason why Th2 LTs were studied for adoptive therapies, with good effect (52).

The Th17 subset is polarized in the presence of IL1 $\beta$, IL6, IL23 and TGF $\beta$ and they secrete ILs 17, 22 and 26, through which they sustain the tumor growth (53). There is a plasticity of the Th17 cells, which can be reprogrammed in Th1 or Treg lymphocytes (54). As in the case of the Th2 subset, the initial view that Th17 is protumoral was reconsidered in the light of some data that showed a beneficial role, especially in adoptive therapy, with success even in cases that were $\mathrm{CD}^{+}$and Th1-resistant $(44,55,56)$ (Table I).

A particularity of the antitumoral immune response is just this combination of subsets that are usually mutually exclusive in the immune response, such as Th1 and Th2; in tumors they seem to coexist and even to cooperate, building an immune defense that is unique to tumors $(44,51)$.

The Th9 subset, through the ILs 9 and 21, which have a stimulatory action on the $\mathrm{CD} 8^{+}$cells, are contributors to the antitumor defense. Th9 lymphocytes also have a direct tumoricidal action (57).

The Th22 subset secretes IL22, whose action is protumoral (58).

$\mathrm{T}$ follicular LTs (Tfh) are associated with good prognosis in many tumors (30). They support the antitumor defense by building the tertiary lymphoid organs in tumors, which are associated with good prognosis (59).

The Treg (T-regulatory) subset polarizes in the presence of TGF $\beta$ from the tumor and associated cells and has an immunosuppressive and by consequence protumoral action through TGF $\beta$ and ILs 10 and 35 that it secretes, and through other inhibitory mechanisms (reviewed in 60) (Table I).

Their presence is associated with poor prognosis (61). An exception is represented by tumors in which there is a strong inflammatory component, where the presence of the Tregs is beneficial (62). They are considered for inhibition through different strategies $(60,62)$ (Table I).

$B$ lymphocytes. They are antitumoral in some tumors such as breast, hepatocellular, gastric and biliary tumors, while being protumoral in others (melanoma, pancreatic, lung, oral cancers) (reviewed in 63) through different mechanisms (64) (Table I).

A more detailed review of the pro and antitumoral role of the mentioned cell types of in tumors, along with the factors that drive their pro or antitumoral state, can be found in Table I and in some other recent works (30).

\section{The tumor microenvironment, from biogenesis to complex relations}

Complicated networks are generated through the interaction of these cells, having as result either the promotion or the inhibition of the tumoral growth. In a previous work, we have reviewed these pro and antitumoral networks, the way in which they interact and the therapeutic opportunities that the understanding of these complex relations may open to immunotherapy (65). In the present study, these networks are analyzed in their dynamics, starting from the biogenesis of the TME, with the same objective of exploring the ways in which the knowledge of this network structure may help to improve therapy.

\section{The biogenesis of the tumor microenvironment}

Angiogenesis and stromagenesis. In their continuous expansion and proliferation, tumor cells arrive at a certain point where they become hypoxic and they need to build a vascular network.

Some studies show that hypoxia does not have any role, the activation of the oncogene being enough to cause the overexpression of angiogens (66); other studies also reveal a hypoxia- and Hif-1-dependent mechanism (67). In fact, to the embryo, a main regulator of angiogenesis is the partial pressure of $\mathrm{O}_{2}\left(\mathrm{PpO}_{2}\right)$.

It has been shown that the angiogenic switch takes place early in the evolution of tumors, even in the premalignant stages (18).

Stromagenesis. The tumor cells secrete FGF, through which they recruit fibroblasts from the surrounding tissues; other sources of fibroblasts are thought to be the endothelial and the tumor cells, through metaplasia. The fibroblasts secrete the ECM, which is dysregulated in tumors, with a different collagen content and structurally altered, compared to normal ECM (11).

Recruitment of cells in tumors. The tumors secrete chemokines: CCL2, IL8, CXCL12, CXCL1, 2, 3, GM-CSF, CCL 5, CCL17, sometimes also anti-tumoral chemokines CXCL9 and 10. This leads to the accumulation of monocytes, neutrophils, regulatory lymphocytes (68).

The cells arrive in tumors for several reasons: they enter, as in any tissue, due to a basal secretion of chemokines (but dysregulated in cancer); they also enter, in an increased number, in the case of the existence of distress signals from within the tumor. This leads to the overexpression of inflammatory chemokines (IL8, CCL2, 5, CXCL9, 10) and infiltration of the tumor with defensive cells.

It has been shown, under experimental conditions, that the activation of an oncogene leads to the overexpression of chemokines such as IL8, CCL2, CCL17, leading to the infiltration with myeloid or lymphoid cells (69).

Some studies report on auto-inflammation in the tumor because the activation of the EGFR or other oncogenic pathways would also lead to the activation of the $\mathrm{NF} \kappa \mathrm{B}$ pathway with consecutive secretion of IL1, 6, TNF and inflammation of the tumor environment. The NFKB pathway can carry oncogenic mutations itself (reviewed in 70).

This cell infiltration in tumors occurs from early stages of the tumor development, even from preneoplastic stages (71).

Under the influence of tumor-generated factors (IL4, 10, TGF $\beta$, exosomes), these cells acquire a protumoral profile, of tissue reconstruction and immune suppression (M2, N2, Treg) (72). 
Immature myeloid cell recruitment. Tumor-secreted factors (IL1, IL6, GM-CSF, TGF $\beta$, CXCL12) act at the level of the bone marrow and trigger an accelerated myelopoiesis, having as result immature myeloid cells (MDSCs), which accumulate in the tumor, leading to immunosuppression and favoring tumor growth (73). This phenomenon is more advanced as the tumor progresses.

Immune suppression in tumors. The tumor microenvironment is immunosuppressive. This immunosuppression takes place through a few mechanisms, from which: the overexpression of inhibitory molecules by the tumor and by the tumor-associated cells (PDL-1, B7-H3, TIM-3 ligands, CD47) and of death factors (FasL); cytokines such as TGF $\beta$, ILs 4, 10, 35; secretion of exosomes with immunosuppressive content; recruitment of suppressive cells (Treg, M2, MDSCs); metabolites (lactate, adenosine), hypoxia, increased hydrostatic pressure in tumors (Fig. 1) (reviewed in 74). The nature of this immunosuppression becomes more clear from some experiments with conditionally activated oncogenes; it has been shown that following the oncogene inactivation, the TME was infiltrated by immune cells $\left(\mathrm{CD}^{+}\right.$, NK LTs), that destroyed tumors (75). Insight into the mechanisms of this relation between oncogenes and immunity showed that activation of Myc led to the upregulation of both CD47 and PDL-1 on the tumor cells (76).

The immunosuppression was an effect of the oncogene activation, along with the others mentioned above (angiogenesis, cell recruitment).

The level of immunosuppression is directly correlated with the tumor progression (74). Other characteristics complete the picture of the TME:

Physico-chemical qualities of the ECM: high hydrostatic pressure, hypoxia, high lactate and adenosine content, IDO-Indoleamine 2, 3-dioxygenase-from MDSCs (77).

Inflammation: In tumors, inflammation can be both pro or antitumoral. It has been shown that inflammation exerts a tumor-promoting role in cancer, through multiple mechanisms such as angiogenesis, release of genotoxic product like ROS, enhanced survival, stimulation of proliferation, stemness or invasion of tumor cells (reviewed in 70); this is true especially with regard to chronic inflammation. On the contrary, experimental data also support a positive role of inflammation in cancer (78). This happens especially in the presence of a strong Th1 component and in the acute phase of inflammation (79).

Proliferation, angiogenesis, cell recruitment and immune suppression - a coordinated program? The events that occur in the TME (proliferation, angiogenesis, cell recruitment and immune suppression) are recognized hallmarks of cancer (80). Considering them as a whole made some researchers compare tumors to a tissue regeneration process, like the one that occurs after a tissue destruction or after the resolution of an infection (81).

This program is triggered by stimuli such as growth factors or signals of termination of the immune response, and has the same components: cell multiplication, angiogenesis, recruitment of cells with regeneration potential (macrophages, neutrophils, fibroblasts, Tregs, epitheliocytes) and immunosuppression.
The program is stopped when signals of tissue integrity and completion (integrin or cadherin signaling, hippo pathway signals) are received.

By contrast, in cancer the program is started aberrantly by the activation of oncogenes, is dysregulated and does not respond to stop signals.

There is some experimental evidence that supports this analogy (82). The comparison is not $100 \%$ accurate, but it can serve as starting point for some therapeutic considerations (83).

Immune response in tumors. The presence of the danger signals from the hypoxic or necrotic tumor cells triggers an innate response from macrophages, neutrophils, mast cells and eosinophils, directed against the tumor.

On the other hand, dysregulation of MHC provokes a tumoricidal response from the NK LTs, while particular antigens, phosphoantigens or lipids, will awake the response of cells like $\gamma \delta$ or NKT-1 cells.

The antigen presentation from antigen-presenting cells (APCs) such as DCs, but also B-lymphocytes (LBs), macrophages and even neutrophils, mast cells or eosinophils opens the way for the intervention of $\mathrm{CD}^{+} \mathrm{CTLs}$, which is completed by the activation of CD4 T-helper lymphocytes, with their effector mechanisms (effector cells of Th subsets, M1 macrophages, neutrophils and eosinophils) (Fig. 2) $(3,84)$.

There is an adequacy of the immune response to a large array of stimuli. The diversity of signals and antigens in tumors requires the deployment of such a great diversity of cells, as mentioned above. The immune response is multimodal and adequate to all types of antigens and stimuli.

There is also a cooperativity in the immune response, as indicated in the first section and in Table I. This cooperation occurs between the cells of the innate immunity, between the innate and adaptive immunity and, finally, within the adaptive response (Fig. 2).

The immune system, with a complexity far beyond what could be described in this review, is still working as a unit, but a unit with adaptable modules (85). This unity is achieved through a network of signals between cells, both soluble (interleukins, chemokines), exosomal and through direct contact through cell adhesion, co-stimulation and co-inhibition.

The immune system is extremely efficient. A great body of experimental evidence shows that innate cells such as macrophages, neutrophils, eosinophils, NK, NKT or $\gamma \delta$ cells can be strong tumoricidal elements, sometimes completely eradicating tumors (86). Clinical evidence from the above-mentioned prognostic association (30) and from new treatments such as bispecific antibodies also shows that there is an extreme efficiency of the lymphocyte when it faces the tumor cells (87).

Unfortunately, this is not always the situation in tumors. They are not eradicated, but continue to grow in spite of such a powerful system that is directed against them.

What are the reasons for this situation? The answer resides in the way in which the immune system and the tumors interact.

Interaction between the immune system and tumors. The first problem that the immune system encounters is the nature of the tumor antigens: they are not true non-self elements, 


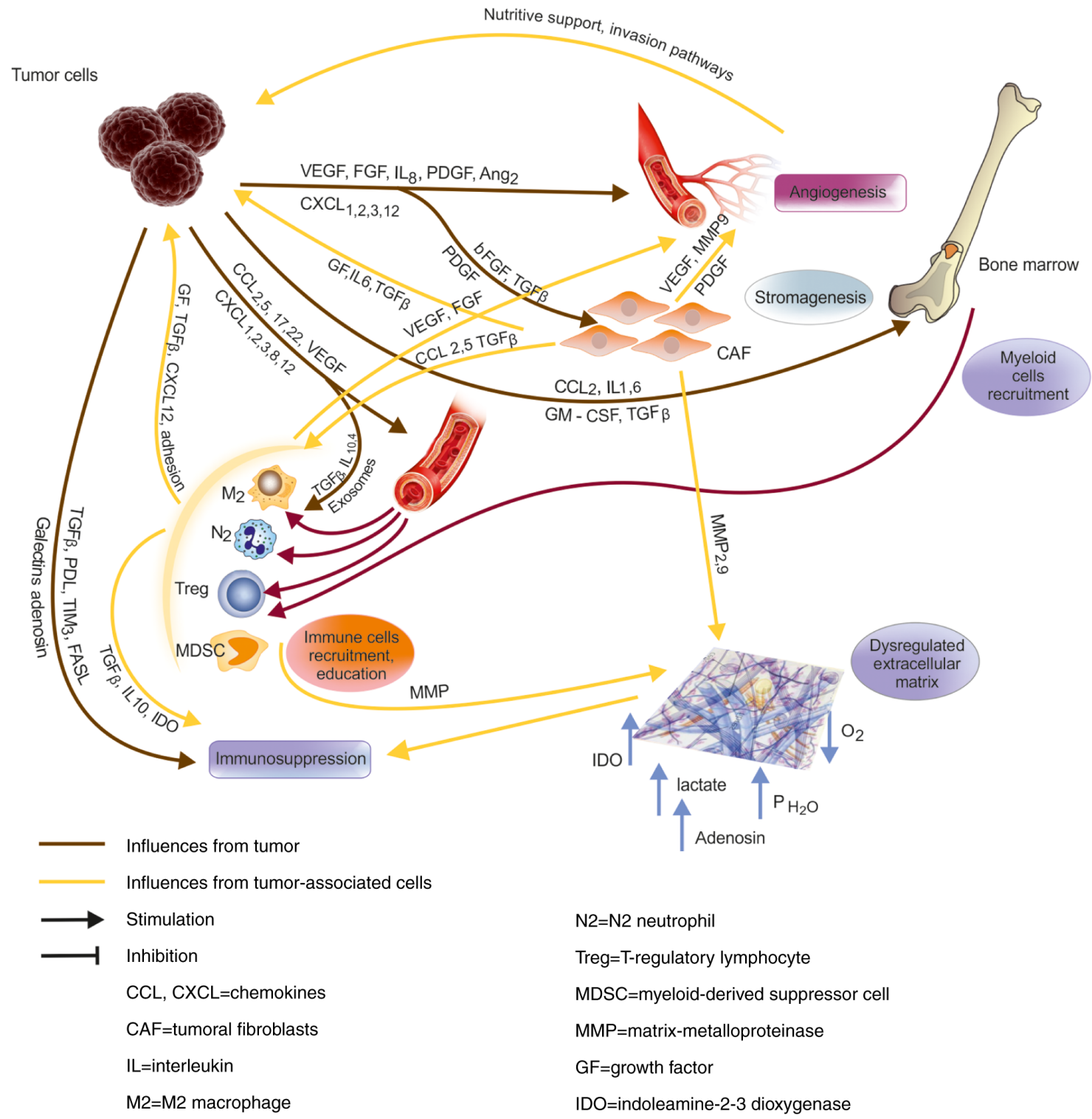

Figure 1. Biogenesis of the tumor microenvironment. The development of the tumor leads to angiogenesis and to recruitment of different cells in the tumor; immunosuppression appears also as a consequence of the tumoral growth. The tumoral fibroblasts secrete a dysregulated extracellular matrix which contributes to the immune suppression. Complex relations are established between the resulting microenvironment components.

but rather an altered self. There are also many stop signals for immunocytes in tumors, such as CD-47 or PD-L1. The tumor antigens are changing through mutations of an unstable genome, another hallmark of cancer (80).

Another problem is represented by the physico-chemical qualities of the environment in which these cells work; in tumors there is acidosis, lactate, hypoxia, IDO and an increased hydrostatic pressure; the blood vessels are modified and do not offer enough cell adhesion molecules (CAMs) for extravasation of leukocytes. By consequence, the immune response is weakened and less efficient (77).

Furthermore, there is immune suppression in tumors; the lymphocytes have to overcome this barrier as well, which they do, but at the expense of losing much of the efficiency of their response. They finally become exhausted and ineffective against tumors (74).

A major problem is that innate immune cells, that prove so tumoricidal in experiments, are subjects of tumor-secreted factors that transform them into cells supporting the tumor. The lymphocytes of the adaptive response lose the important support of these cells, weakening once more in their capacity of response (88).

A seemingly paradoxical situation is that some of the components of the immune response in tumors have protumoral effects themselves; this is the case of the chronic, smoldering inflammation that accompanies tumors, and also of some types of adaptive response, the Th2, Th17 response, some $\gamma \delta$ or NKT-cell subsets, as mentioned earlier (Table I and Fig. 3). This situation is caused by the fact that interleukins can act as growth factors, can promote angiogenesis especially in a situation of chronic inflammation and, acting on epithelia, including tumor cells, they can promote proliferation and cell survival (reviewed in 65).

Finally, the dysfunction of the dendritic cell in tumors leads to a misbalance between lymphocyte subsets, with a 


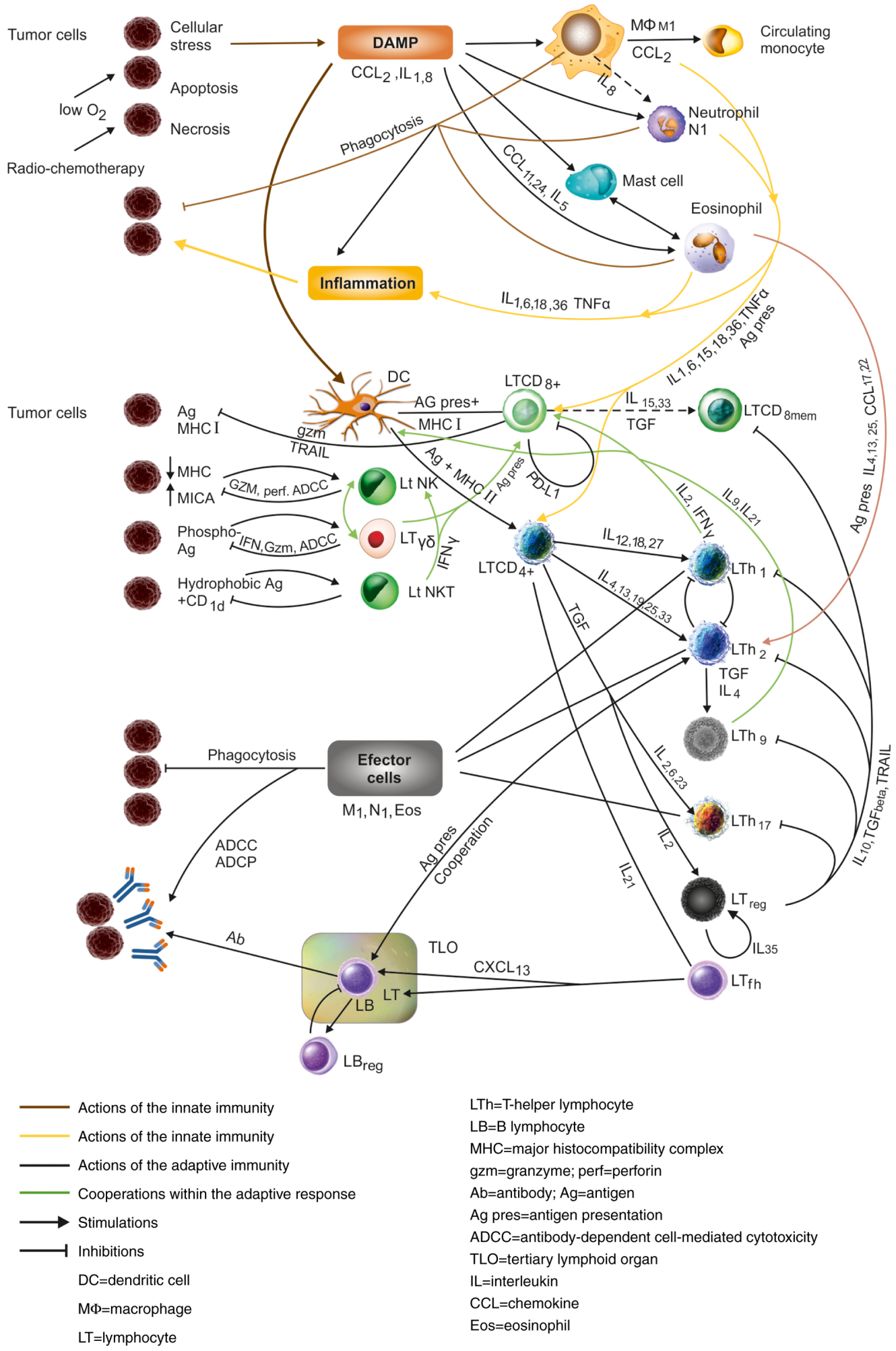

Figure 2. Immune response in malignant tumors. The presence of the danger signals within the tumor triggers an innate immune response; the antigen presentation by the APCs (antigen-presenting cells) leads to the activation of the $\mathrm{CD}^{+}$and $\mathrm{CD}^{+}$lymphocytes; low level of MHC proteins or increased atypical MHC such as MICA activate NK lymphocytes, while particular subsets such as $\gamma \delta$ or NKT-cells respond to antigens like phospho-antigens or CDld-presented lipidic antigens. A multimodal immune response develops, adequate to the signals that the tumor presents. The different segments of the immune system cooperate for an optimal response.

bias towards Th2 and regulatory subsets and a decrease of the Th1-M1 subsets. As shown earlier, it is this misbalance that is harmful to the antitumor defense, and in this situation, Th2 and Th17 lose most of their antitumoral activity and become mainly protumoral (42).
As a result, the immune system becomes gradually inefficient and the tumors continue to grow.

Varieties of tumor microenvironment. Tumors are heterogeneous structures and their TME differs from one tumor to 


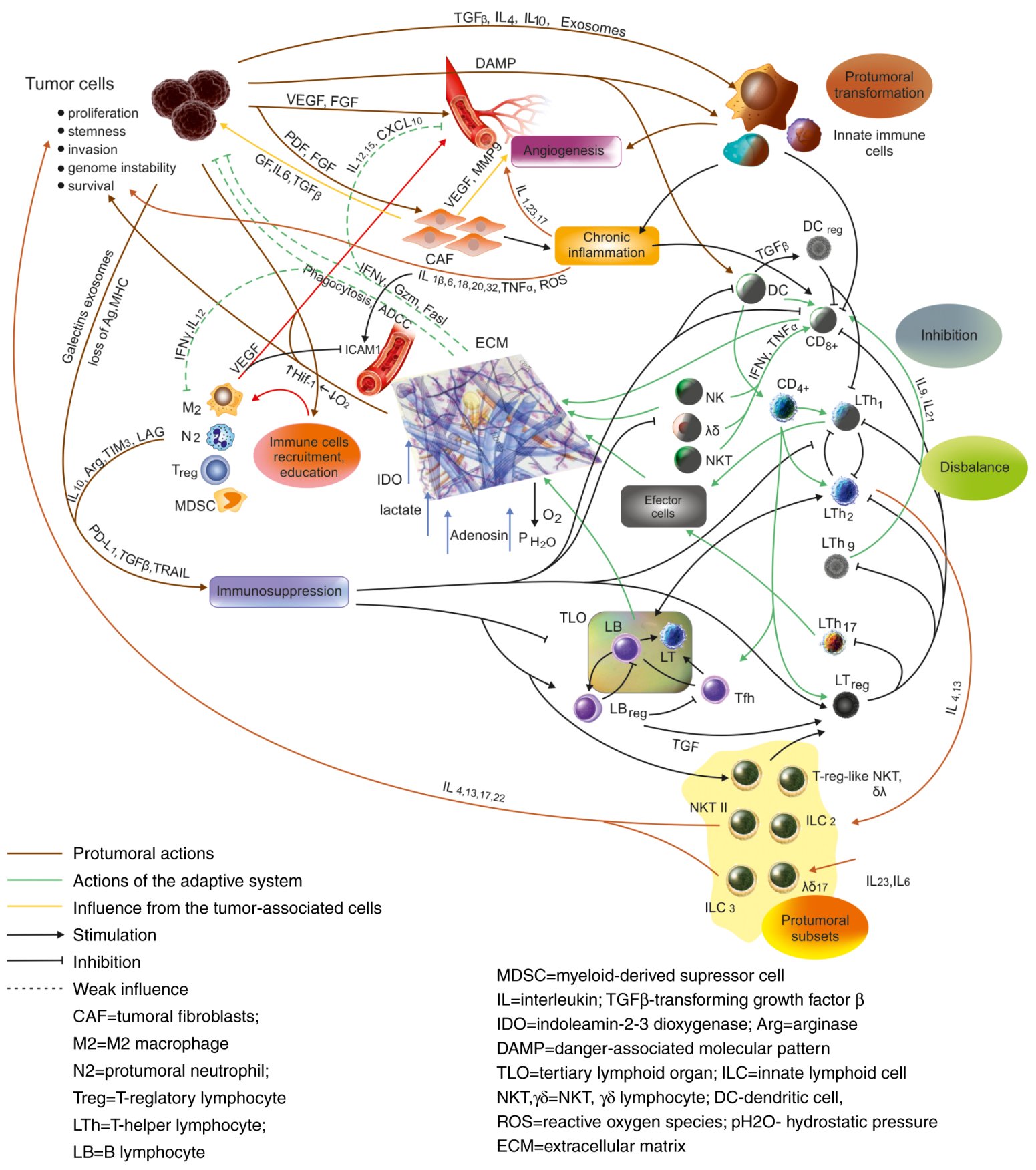

Figure 3. Relations between the tumor and the immune response. The immune response and tumors interact in multiple ways. The immunosuppression from the tumor microenvironment inhibits the antigen-specific lymphocytes, while innate immune cells are influenced by tumor-derived factors, cytokines and exosomes to aquire a protumoral profile. The dysregulated extracellular matrix contributes to the suppression, increasing also the survival and the invasiveness of the tumor cells; chronic inflammation that develops supports the tumoral growth, while certain profiles of adaptive response such as Th2 or Th17 are also mainly protumoral.

another. A recent study showed that there are at least six types of TME in tumors, based on which of these networks predominate, the subtype with angiogenesis, with inflammation, interferon-dominant, TGF $\beta$-dominant, lymphocyte-depleted and immunologically quiet tumors. The authors suggest that these data should be incorporated in the future strategies of cancer therapy (89).

There are also differences between the different locations of tumors (90), between stages and even between patients. The type of carcinogen may also cause differences concerning not only the genomic alterations, but also the profile of the immune response that follows $(91,92)$. These differences between tumors should prompt the development of more personalized approaches in immunotherapy (93). Personalized approaches are a developing field, and they involve the use of biomarkers such as tissue expression of checkpoint molecules, serum cytokines profile or proteomic approaches to direct precision targeted therapy of tumors $(93,94)$.

The role of neuroendocrine factors. To complete the picture of networks in tumors, the role of the neuro-endocrine factors has to be mentioned; indeed, there is experimental data that demonstrate an influence of the nervous and endocrine system on the 

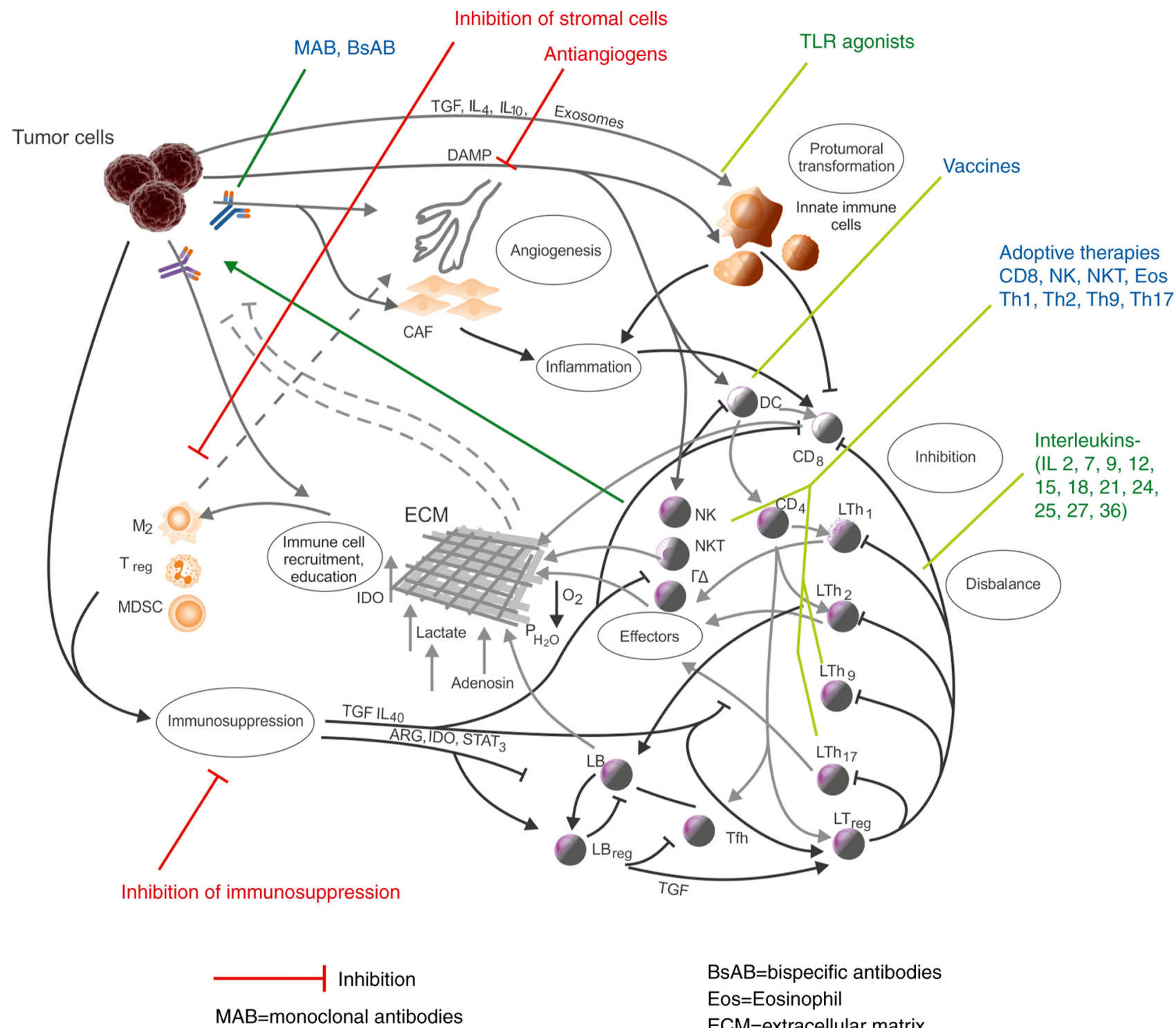

BsAB=bispecific antibodies
Eos=Eosinophil
$E C M=$ extracellular matrix

Figure 4. Immunotherapy adresses tumors by inhibiting angiogenesis, tumor-associated cells and immunosuppression, and also by stimulating different cells with tumoricidal potential, through antibodies (monoclonal or bispecific), adoptive therapies, vaccines, TLR stimulation or interleukins. A network view of the different immunotherapies is shown.

immune response (95). This is also true for the tumor immunology, since both immunocytes (96) and cancer cells (97) possess receptors for catecholamines, cortisol or different neuropeptides. This fact can be therapeutically exploited, where there are receptors in the tumor. It has been shown that through these receptors, the nervous and the endocrine systems can modulate the tumoral growth and invasion (98). The neuroendocrine factor, and through it the psychological factor, proved to be not neglectable factors in influencing the prognosis of patients with tumors.

Networks and immunotherapy. A new factor, immunotherapy, has recently entered this dynamic relation between tumors and the immune system.

One side of the immunotherapy is an inhibitory one, which addresses the tumoral side of the environment; its targets are angiogenesis (99), tumor associated cells (100), immuno-suppression (101) and inflammation (70).
Another side is the positive immunotherapy, which uses parts of the immune response to attack tumors. Antibodies (monoclonal or bispecific) are used to direct immune cells against the tumor cells, immune cells themselves are used in adoptive therapy, vaccines are used to strengthen the antigen-specific response, TLR agonists are used to stimulate innate cells, and interleukins are used to stimulate the defense $(101,102)$ (Fig. 4).

Immunotherapies must be considered in the larger frame of immune networks in tumors; such a perspective opens the way of new strategies, which result from the network structure of the TME (103) and completes intelligent approaches like bispecific antibodies, CAR-engineered lymphocytes or the attempt to modify the antigenic interface of tumors (104). Undoubtedly these are efficient therapeutic means and have proven results, but they also have limitations, which may, at least partially, be due to the existence of these inhibitory loops that work in the TME. 
Subsequently, the analysis of the immune networks in tumors is an area of increasing interest, because it is expected to offer solutions based on the understanding of the structure of these networks in the TME.

\section{Conclusions and perspectives}

The present study is an attempt to decipher the complex pro and antitumoral networks that form and interact in the tumor microenvironment.

The study underlines the great potential of immunotherapies; however, based on the existence of this network structure of the TME, it suggests that therapeutic approaches should be network-based and should take into account all these complex interactions within the microenvironment of tumors.

At present, performant imaging and computational approaches going as far as the single-cell level begin to enter clinic (105), computer-based learning is used to project anticancer molecules (106), but also network medicine begins to enter all fields of pathology (107), including tumor immunology and immunotherapy.

Immunotherapy is at its beginnings, but much progress has been done in recent years, based on the growing knowledge of immunobiology and genomics of malignant tumors.

Apart from the progress in the molecular and cellular biology, the knowledge of the tumor microenvironment as a whole, with its complex network of cells and cytokines, will contribute to the development of the immune therapy in the years to come.

\section{Acknowledgements}

Professional editing, linguistic and technical assistance performed by Irina Radu, Individual Service Provider, certified translator in Medicine and Pharmacy (certificate credentials: Series E no. 0048).

\section{Funding}

No funding was received.

\section{Availability of data and materials}

Not applicable.

\section{Authors' contributions}

OF contributed in the conception of the study and wrote the manuscript. VC contributed in the conception of the study and revised it critically for important intellectual content. Both authors read and approved the final manuscript and agreed to be accountable for all aspects of the work.

\section{Ethics approval and consent to participate}

Not applicable.

\section{Patient consent for publication}

Not applicable.

\section{Competing interests}

The authors declare that they have no competing interests.

\section{References}

1. Egeblad M, Nakasone ES and Werb Z: Tumors as organs: Complex tissues that interface with the entire organism. Dev Cell 18: 884-901, 2010.

2. de Visser KE, Eichten A and Coussens LM: Paradoxical roles of the immune system during cancer development. Nat Rev Cancer 6: 24-37, 2006.

3. Murphy K, Weaver C and Janeway C: Janeway's immunobiology. 9th edition. New York, Garland Science, 2017.

4. Xue J, Schmidt SV, Sander J, Draffehn A, Krebs W, Quester I, De Nardo D, Gohel TD, Emde M, Schmidleithner L, et al: Transcriptome-based network analysis reveals a spectrum model of human macrophage activation. Immunity 40: 274-288, 2014.

5. Aras S and Zaidi MR: TAMeless traitors: Macrophages in cancer progression and metastasis. Br J Cancer 117: 1583-1591, 2017

6. Kawai O, Ishii G, Kubota K, Murata Y, Naito Y, Mizuno T, Aokaje K, Saijo N, Nishiwaki Y, Gemma A, et al: Predominant infiltration of macrophages and CD8(+) T cells in cancer nests is a significant predictor of survival in stage IV nonsmall cell lung cancer. Cancer 113: 1387-1395, 2008.

7. Ryder M, Ghossein RA, Ricarte-Filho JC, Knauf JA and Fagin JA: Increased density of tumor-associated macrophages is associated with decreased survival in advanced thyroid cancer. Endocr Relat Cancer 15: 1069-1074, 2008.

8. Georgoudaki AM, Prokopec KE, Boura VF, Hellqvist E, Sohn S, Östling J, Dahan R, Harris RA, Rantalainen M, Klevebring D, et al: Reprogramming tumor-associated macrophages by antibody targeting inhibits cancer progression and metastasis. Cell Rep 15: 2000-2011, 2016.

9. Phan SH: Biology of fibroblasts and myofibroblasts. Proc Am Thorac Soc 5: 334-337, 2008

10. Chang HY, Chi JT, Dudoit S, Bondre C, van de Rijn M, Botstein D and Brown PO: Diversity, topographic differentiation, and positional memory in human fibroblasts. Proc Nat Acad Sci USA 99: $12877-12882,2002$.

11. Dumont N, Liu B, Defilippis RA, Chang H, Rabban JT, Karnezis AN, Tjoe JA, Marx J, Parvin B and Tlsty TD: Breast fibroblasts modulate early dissemination, tumorigenesis, and metastasis through alteration of extracellular matrix characteristics. Neoplasia 15: 249-262, 2013.

12. Gascard P and Tlsty TD: Carcinoma-associated fibroblasts: Orchestrating the composition of malignancy. Genes Dev 30: 1002-1019, 2016.

13. Michiels C: Endothelial cell functions. J Cell Physiol 196: 430-443, 2003

14. Zhang L, Yang N, Park JW, Katsaros D, Franchiolli S, Cao G, O'Brien-Jenkins A, Randall TC, Rubin SC and Coukos G: Tumor-derived vascular endothelial growth factor upregulates angiopoietin-2 in host endothelium and destabilizes host vasculature, supporting angiogenesis in ovarian cancer. Cancer Res 63: 3403-3412, 2003 .

15. Konerding MA, Malkusch W, Klapthor B, van Ackern C, Fait E, Hill SA, Parkins C, Chaplin DJ, Presta $M$ and Denekamp J: Evidence for characteristic vascular patterns in solid tumours: Quantitative studies using corrosion casts. Br J Cancer 80: 724-732, 1999.

16. Mócsai A: Diverse novel functions of neutrophils in immunity, inflammation, and beyond. J Exp Med 210: 1283-1299, 2013.

17. Fridlender ZG, Sun J, Kim S, Kapoor V, Cheng G, Ling L, Worthen GS and Albelda SM: Polarization of tumor-associated neutrophil phenotype by TGF-beta: 'N1' versus 'N2' TAN. Cancer Cell 16: 183-194, 2009.

18. Nozawa H, Chiu C and Hanahan D: Infiltrating neutrophils mediate the initial angiogenic switch in a mouse model of multistage carcinogenesis. Proc Natl Acad Sci USA 103: 12493-12498, 2006.

19. Jensen HK, Donskov F, Marcussen N, Nordsmark M, Lundbeck F and von der Maase H: Presence of intratumoral neutrophils is an independent prognostic factor in localized renal cell carcinoma. J Clin Oncol 27: 4709-4717, 2009.

20. Walsh SR, Cook EJ, Goulder F, Justin TA and Keeling NJ: Neutrophil-lymphocyte and ratio as a prognostic factor in colorectal cancer. J Surg Oncol 91: 181-184, 2005. 
21. Shamri R, Xenakis JJ and Spencer LA: Eosinophils in innate immunity: An evolving story. Cell Tissue Res 343: 57-83, 2011.

22. Carretero R, Sektioglu IM, Garbi N, Salgado OC, Beckhove P and Hämmerling GJ: Eosinophils orchestrate cancer rejection by normalizin tumor vessels and enhancing infiltration of CD8(+) T cells. Nat Immunol 16: 609-617, 2015.

23. Akdis M, Aab A, Altunbulakli C, Azkur K, Costa RA, Crameri R, Duan S, Eiweger T, Eljaszewicz A, Ferstl R, et al: Interleukins (from IL-1 to IL-38), interferons, transforming growth factor $\beta$ and TNF- $\alpha$ : Receptors, functions, and roles in diseases. J Allergy Clin Immunol 138: 984-1010, 2016.

24. Mattes J, Hulett M, Xie W, Hogan S, Rottenberg ME, Foster P and Parish C: Immunotherapy of cytotoxic T cell-resistant tumors by T helper 2 cells: An eotaxin and STAT6-dependent process. J Exp Med 197: 387-393, 2003

25. Tepper RI, Pattengale PK and Leder P: Murine interleukin-4 displays potent anti-tumor activity in vivo. Cell 57: 503-512, 1989

26. Fernández-Aceñero MJ, Galindo-Gallego M, Sanz J and Aljama A: Prognostic influence of tumor-associated eosinophilic infiltrate in colorectal carcinoma. Cancer 88: 1544-1548, 2000.

27. Krystel-Whittemore M, Dileepan KN and Wood JG: Mast cell: A multi-functional master cell. Front Immunol 6: 620, 2016.

28. Varricchi G, Galdiero MR, Loffredo S, Marone G, Iannone R, Marone G and Granata F: Are mast cells MASTers in cancer? Front Immunol 8: 424, 2017.

29. Oldford SA, Haidl ID, Howatt MA, Leiva CA, Johnston B and Marshall JS: A critical role for mast cells and mast cell-derived IL-6 in TLR2-mediated inhibition of tumor growth. J Immunol 185: 7067-7076, 2010.

30. Gentles AJ, Newman AM, Liu CL, Bratman SV, Feng W, Kim W, Nair SW, Xu H, Khuong A, Hoang CD, et al: The prognostic landscape of genes and infiltrating immune cells across human cancers. Nat Med 21: 938-945, 2015.

31. Patil RS, Shah SU, Shrikhande SV, Goel M, Dikshit RP and Chiplunkar SV: IL17 producing $\gamma \delta$ T cells induce angiogenesis and are associated with poor survival in gallbladder cancer patients. Int J Cancer 139: 869-881, 2016.

32. Zhao Y, Niu C and Cui J: Gamma-delta $(\gamma \delta)$ T cells: Friend or foe in cancer development? J Transl Med 16: 3, 2018.

33. Dhodapkar MV and Kumar V: Type II NKT cells and their emerging role in health and disease. J Immunol 198: 1015-1021, 2017.

34. Terabe M, Matsui S, Noben-Trauth N, Chen H, Watson C, Donaldson DD, Carbone DP, Paul WE and Berzofsky JA: NKT cell-mediated repression of tumor immunosurveillance by IL-13 and the IL-4R-STAT6 pathway. Nat Immunol 1: 515-520, 2000.

35. Terabe M and Berzofsky JA: The role of NKT cells in tumor immunity. Adv Cancer Res 101: 277-348, 2008.

36. Yang Q, Goding SR, Hokland ME and Basse PH: Antitumor activity of NK cells. Immunol Res 36: 13-25, 2006.

37. Minetto P, Guolo F, Pesce S, Greppi M, Obino V, Ferretti E, Sivori S, Genova C, Lemoli RM and Marcenaro E: Harnessing NK cells for cancer treatment. Front Immunol 10: 2836, 2019.

38. van Beek JJP, Martens AWJ, Bakdash G and de Vries IJM: Innate lymphoid cells in tumor immunity. Biomedicines 4: 7, 2016.

39. Eisenring M, vom Berg J, Kristiansen G, Saller E and Becker B: IL-12 initiates tumor rejection via lymphoid tissue-inducer cells bearing the natural cytotoxicity receptor NKp46. Nat Immunol 11: 1030-1038, 2010.

40. Mellman I: Dendritic cells: Master regulators of the immune response. Cancer Immunol Res 1: 145-149, 2013

41. Lijun Z, Xin Z, Danhua S, Xiaoping L, Jianliu W, Huilan W and Lihui W: Tumor-infiltrating dendritic cells may be used as clinicopathologic prognostic factors in endometrial carcinoma. Int J Gynecol Cancer 22: 836-841, 2012.

42. Ma Y, Shurin GV, Peiyuan Z and Shurin MR: Dendritic cells in the cancer microenvironment. J Cancer 4: 36-44, 2013.

43. Zhan Y and Wu L: Functional regulation of monocyte-derived dendritic cells by microRNAs. Protein Cell 3: 497-507, 2012.

44. Ostroumov D, Fekete-Drimusz N, Saborowski M, Kühnel F and Woller N: CD4 and CD8 T lymphocyte interplay in controlling tumor growth. Cell Mol Life Sci 75: 689-713, 2018.

45. Woo SR, Turnis ME, Goldberg MV, Bankoti J, Selby M, Nirschl CJ, Bettini ML Gravano DM, Vogel P, Liu CL, et al: Immune inhibitory molecules LAG-3 and PD-1 synergistically regulate T-cell function to promote tumoral immune escape. Cancer Res 72: 917-927, 2012.

46. Ziai J, Gilbert HN, Foreman O, Eastham-Anderson J, Chu F, Huseni $\mathrm{M}$ and Kim JM: $\mathrm{CD}^{+} \mathrm{T}$ cell infiltration in breast and colon cancer: A histologic and statistical analysis. PLoS One 13: e0190158, 2018
47. Durgeau A, Virk Y, Corgnac S and Mami-Chouaib F: Recent advances in targeting CD8 T-cell immunity for more effective cancer immunotherapy. Front Immunol 9: 14, 2018.

48. Akbulut G, Özkazanç D and Esendağlı G: Th1 cells in cancer-associated inflammation. Turk J Biol 41: 20-30, 2017.

49. Bos R and Sherman LA: CD4 ${ }^{+}$T-cell help in the tumor milieu is required for recruitment and cytolytic function of $\mathrm{CD} 8^{+}$ T lymphocytes. Cancer Res 70: 8368-8377, 2010.

50. Fujisawa T, Joshi BH and Puri RK: IL-13 regulates cancer invasion and metastasis through IL-13R $\alpha 2$ via ERK/AP-1 pathway in mouse model of human ovarian cancer. Int J Cancer 131: 344-356, 2012

51. Nishimura T, Iwakabe K, Sekimoto M, Ohmi Y, Yahata T, Nakui M, Sato T, Habu S, Tashiro H, Sato M and Ohta A: Distinct role of antigen-specific t helper type 1 (Th1) and Th2 cells in tumor eradication in vivo. J Exp Med 190: 617-627, 1999.

52. Lorvik KB, Hammarström C, Fauskanger M, Haabeth OA, Zangani M, Haraldsen G, Bogen B and Corthay A: Adoptive transfer of tumor-specific Th2 cells eradicates tumors by triggering an in situ inflammatory immune response. Cancer Res 76: 6864-6876, 2016

53. Amicarella F, Muraro MG, Hirt C, Cremonesi E, Padovan E, Mele V, Governa V, Han J, Huber X, Droeseret RA, et al: Dual role of tumour-infiltrating T helper 17 cells in human colorectal cancer. Gut 66: 692-704, 2017.

54. Lee YK, Turner H, Maynard CL, Oliver JR, Chen D, Elson CO and Weaver CT: Late developmental plasticity in the Thelper 17 lineage. Immunity 30: 92-107, 2009.

55. Kryczek I, Banerjee M, Cheng P, Vatan L, Szeliga W, Wei S, Huang E, Finlayson E, Simeone D, Welling TH, et al: Phenotype, distribution, generation, and functional and clinical relevance of Th17 cells in the human tumor environments. Blood 114: 1141-1149, 2009.

56. Martin-Orozco N, Muranski P, Chung Y, Yang XO, Yamazaki T, Lu S, Hwu P, Restifo NP, Overwijk WW and Dong C: T helper 17 cells promote cytotoxic $\mathrm{T}$ cell activation in tumor immunity. Immunity 31: 787-798, 2009.

57. Lu Y, Hong S, Li H, Park J, Hong B, Wang L, Zheng Y, Liu Z, $\mathrm{Xu} \mathrm{J}, \mathrm{He} \mathrm{J}$, et al: Th9 cells promote antitumor immune responses in vivo. J Clin Invest 122: 4160-4171, 2012.

58. Kim K, Kim G, Kim JY, Yun HJ, Lim SC and Choi HS: Interleukin-22 promotes epithelial cell transformation and breast tumorigenesis via MAP3K8 activation. Carcinogenesis 35: $1352-1361,2014$

59. Gu-Trantien C, Loi S, Garaud S, Equeter C, Libin M, de Wind A, Ravoet M, Le Buanec H, Sibille C, Manfouo-Foutsop G, et al: CD4' follicular helper T cell infiltration predicts breast cancer survival. J Clin Invest 123: 2873-2892, 2013

60. Verma A, Mathur R, Farooque A, Kaul V, Gupta S and Dwarakanath BS: T-regulatory cells in tumor progression and therapy. Cancer Manag Res 11: 10731-10747, 2019.

61. Facciabene A, Motz GT and Coukos G: T-regulatory cells: Key players in tumor immune escape and angiogenesis. Cancer Res 72: 2162-2171, 2012

62. Correale P, Rotundo MS, Del Vecchio MT, Remondo C Migali C, Ginnaneschi C, Tsang KY, Lichetta A, Manucci S, Loiacono L, et al: Regulatory (FoxP3 ${ }^{+}$) T-cell tumor infiltration is a favorable prognostic factor in advanced colon cancer patients undergoing chemo or chemoimmunotherapy. J Immunother 33: 435-441, 2010.

63. Wouters MCA and Nelson BH: Prognostic significance of tumor-infiltrating B cells and plasma cells in human cancer. Clin Cancer Res 24: 6125-6135, 2018

64. Yuen GJ, Demissie E and Pillai S: B lymphocytes and cancer: A love-hate relationship. Trends Cancer 2: 747-757, 2016.

65. Farc O and Cristea V: Pro-and antitumor role of interleukins 1 to 41. Roum Arch Microbiol Immunol 78: 149-162, 2019.

66. Figueras A, Arbos MA, Quiles MT, Viñals F, Germà JR and Capellà G: The impact of KRAS mutations on VEGF-A production and tumour vascular network. BMC Cancer 13 $125,2013$.

67. Talks KL, Turley H, Gatter KC, Maxwell PH, Pugh CW, Ratcliffe PJ and Harris AL: The expression and distribution of the hypoxia-inducible factors HIF-1alpha and HIF-2alpha in normal human tissues, cancers, and tumor-associated macrophages. Am J Pathol 157: 411-421, 2000.

68. Hill BS, Sarnella A, D'Avino G and Zannetti A: Recruitment of stromal cells into tumour microenvironment promote the metastatic spread of breast cancer. Semin Cancer Biol 60: 202-213, 2020 . 
69. Austenaa L and Natoli G: A shortcut for early macrophage recruitment into tumors by activated oncogenes. Genes Dev 31: 223-225, 2017.

70. Mantovani A, Allavena P, Sica A and Balkwill F: Cancer-related inflammation. Nature 454: 436-444, 2008.

71. Wörmann SM, Diakopoulos KN, Lesina M and Algül H: The immune network in pancreatic cancer development and progression. Oncogene 33: 2956-2967, 2014.

72. Le Naour A, Prat M, Thibault B, Mevel R, Lemaître L, Leray H, Joubert MV, Coulson K, Golzio M, Lefevre L, et al: Tumor cells educate mesenchymal stromal cells to release chemoprotective and immunomodulatory factors. J Mol Cell Biol 12: 202-215, 2020.

73. Bosiljcic M, Cederberg RA, Hamilton MJ, LePard NE, Harbourne BT, Collier JL, Halvorsen EC, Shi R, Franks SE, Kim AY, et al: Targeting myeloid-derived suppressor cells in combination with primary mammary tumor resection reduces metastatic growth in the lungs. Breast Cancer Res 21: 103, 2019.

74. Dunn GP, Old LJ and Schreiber RD: The three Es of cancer immunoediting. Annu Rev Immunol 22: 329-360, 2004.

75. Casey SC, Li Y and Felsher DW: An essential role for the immune system in the mechanism of tumor regression following targeted oncogene inactivation. Immunol Res 58: 282-291, 2014

76. Casey SC, Tong L, Li Y, Do R, Walz S, Fitzgerald KN, Gouw AM, Baylot V, Gütgemann I, Eilers M and Felsher DW: MYC regulates the antitumor immune response through CD47 and PD-L1. Science 352: 227-231, 2016.

77. Xiong GF and Xu R: Function of cancer cell-derived extracellular matrix in tumor progression. J Cancer Metastasis Treat 2 357-364, 2016.

78. Agrawal N, Bettegowda C, Cheong I, Geschwind JF, Drake CG, Hipkiss EL, Tatsumi M, Dang LH, Diaz LA Jr, Pomper M, et al Bacteriolytic therapy can generate a potent immune response against experimental tumors. Proc Natl Acad Sci 101: 15172-15177, 2004

79. Haabeth OA, Bogen B and Corthay A: A model for cancer - suppressive inflammation. Oncoimmunology 1 : 1146-1155, 2012.

80. Hanahan D and Weinberg RA: Hallmarks of cancer: The next generation. Cell 144: 646-674, 2011.

81. Schäfer M and Werner S: Cancer as an overhealing wound: An old hypothesis revisited. Nat Rev Mol Cell Biol 9: 628-63879, 2008.

82. Riss J, Khanna C, Koo S, Chandramoulli DV, Yang HH, Hu Y, Kleiner DE, Rosenward A, Schaeffer CF, Ben-Sasson SA, et al: Cancers as wounds that do not heal: Differences and similarities between renal regeneration/repair and renal cell carcinoma. Cancer Res 66: 7216-7224, 2006.

83. Pesic M and Greten FR: Inflammation and cancer: Tissue regeneration gone awry. Curr Opin Cell Biol 43: 55-61, 2016.

84. Naga A, Siddiqui A and Bindu H: Immuno defense mechanism against tumors. J Cancer Sci Ther 17: 2, 2011.

85. Kondratova M, Czerwinska U, Sompairac N, Amigorena SD, Soumelis V, Barillot E, Zinovyev A and Kuperstein I: A multiscale signalling network map of innate immune response in cancer reveals cell heterogeneity signatures. Nat Commun 10 : 4808, 2019.

86. Liu Y and Zeng G: Cancer and innate immune system interactions: Translational potentials for cancer immunotherapy. J Immunother 35: 299-308, 2012.

87. Wong R, Pepper C, Brennan P, Nagorsen D, Man S and Fegan C: Blinatumomab induces autologous T-cell killing of chronic lymphocytic leukemia cells. Haematologica 98: 1930-1938, 2013

88. Burkholder B, Huang RY, Burgess R, Luo S, Jones VS, Zhang W, Lu ZQ, Gao CY, Wang BL, Zhang YM and Huang RP: Tumor-induced perturbations of cytokines and immune cell networks. Biochim Biophys Acta 1845: 182-201, 2014.
89. Thorsson V, Gibbs DL, Brown SD, Wolf D, Bortone DS, Ou Yang TH, Porta-Pardo E, Gao GF, Plaisier CL, Eddy JA, et al: The immune landscape of cancer. Immunity 48: 812-830.e14, 2018.

90. Ringelhan M, Pfister D, O'Connor T, Pikarsky E and Heikenwalder M: The immunology of hepatocellular carcinoma. Nat Immunol 19: 222-232, 2018.

91. Neagu M, Caruntu C, Constantin C, Boda D, Zurac S, Spandidos DA and Tsatsakis AM: Chemically induced skin carcinogenesis: Updates in experimental models (Review). Oncol Rep 35: 2516-2528, 2016.

92. Boda D, Docea AO, Calina D, Ilie MA, Caruntu C, Zurac S, Neagu M, Constantin C, Branisteanu DE, Voiculescu V, et al: Human papilloma virus: Apprehending the link with carcinogenesis and unveiling new research avenues. Int $\mathrm{J}$ Oncol 52 637-655, 2018.

93. Palucka AK and Coussens LM: The basis of oncoimmunology. Cell 164: 1233-1247, 2016.

94. Ion A, Popa IM, Papagheorghe LM, Lisievici C, Lupu M, Voiculescu V, Caruntu C and Boda D: Proteomic approaches to biomarker discovery in cutaneous T-cell lymphoma. Dis Markers 2016: 9602472, 2016.

95. Grigore O, Mihailescu AI, Solomon I, Boda D and Caruntu C: Role of stress in modulation of skin neurogenic inflammation. Exp Ther Med 17: 997-1003, 2019.

96. Solomon I, Voiculescu VM, Caruntu C, Lupu M, Popa A, Ilie MA, Albulescu R, Caruntu A, Tanase C, Constantin C, et al: Neuroendocrine factors and head and neck squamous cell carcinoma: An affair to remember. Dis Markers 2018: 9787831, 2018

97. Caruntu C, Boda D, Constantin C, Caruntu A and Neagu M: Catecholamines increase in vitro proliferation of murine B16F10 melanoma cells. Acta Endocrinol 10: 545-558, 2014.

98. Lupu M, Caruntu A, Caruntu C, Papagheorghe LML, Ilie MA Voiculescu V, Boda D, Constantin C, Tanase C, Sifaki M, et al: Neuroendocrine factors: The missing link in non melanoma skin cancer (Review). Oncol Rep 38: 1327-1340, 2017.

99. Maj E, Papiernik D and Wietrzyk J: Antiangiogenic cancer treatment: The great discovery and greater complexity (Review). Int J Oncol 49: 1773-1784, 2016.

100. Cotechini T, Medler TR and Coussens LM: Myeloid cells as targets for therapy in solid tumors. Cancer J 21: 343-350, 2015.

101. Kruger S, Ilmer M, Kobold S, Cadilha BL, Endres S, Ormanns S, Schuebe G, Renz BW, D'Haese JG, Schloesser H, et al: Advances in cancer immunotherapy 2019 - latest trends. J Exp Clin Cancer Res 38: 268, 2019.

102. Farkona S, Diamandis EP and Blasutig IM: Cancer immunotherapy: The beginning of the end of cancer? BMC Med 14: 73 2016.

103. Clancy $\mathrm{T}$ and Hovig E: Profiling networks of distinct immune-cells in tumors. BMC Bioinformatics 17: 263, 2016.

104. Munks M, Levitsky V, Hill A and Knoetgen H: Cytomegalovirus-specific CD8 T cells kill B16 melanoma cells in vivo whe activated by bifunctional major histocompatibility class I-antibody fusion molecules (pMHCI-IgGs). J Immunotherapy Cancer 3: 237, 2015.

105. Boda D: Cellomics as integrative omics for cancer. Curr Proteomics 10: 237-245, 2013.

106. Ancuceanu R, Dinu M, Neaga I, Laszlo FG and Boda D: Development of QSAR machine learning-based models to forecast the effect of substances on malignant melanoma cells. Oncol Lett 17: 4188-4196, 2019.

107. Robin X, Creixell P, Radetskaya O, Santini CC, Longden J and Linding R: Personalized network-based treatments in oncology. Clin Pharmacol Ther 94: 646-650, 2013.

This work is licensed under a Creative Commons Attribution-NonCommercial-NoDerivatives 4.0 International (CC BY-NC-ND 4.0) License. 